\title{
REDAÇÃO DA PRIMEIRA VERSÃO DA TRADUÇÃO POR TRADUTORES PROFISSIONAIS E ALUNOS DE TRADUÇÃO ${ }^{1}$
}

\section{TRANSLATION DRAFTING BY PROFESSIONAL TRANSLATORS AND BY TRANSLATION STUDENTS}

\author{
Arnt Lykke JAKOBSEN ${ }^{2}$ \\ Tradução de: Liara Rodrigues de $\mathrm{BRITO}^{3}$
}

\section{Introdução}

Em experimentos conduzidos entre 2000 e 2001, oito tradutores traduziram, cada um, quatro textos diferentes, dois do dinamarquês para o inglês e dois do inglês para o dinamarquês. Quatro deles eram alunos de tradução do último ano (tradutores semiprofissionais) do Departamento de Inglês da Copenhagen Business School (CBS), e quatro eram tradutores profissionais (expertos) com pelo menos dois anos de experiência em tradução após a graduação ${ }^{4}$. Os textos-fonte foram exibidos no Translog, que também gravou detalhes do processo de digitação dos textos-alvo pelos tradutores ${ }^{5}$.

Em Jakobsen (2003), traduzido neste volume, buscou-se determinar o efeito da verbalização concomitante do pensamento em voz alta (do inglês, think aloud protocol, ou TAP) na velocidade da tradução, na revisão e na segmentação. Todas as medições se basearam em tarefas completas de tradução. No presente artigo, procedeu-se a uma nova divisão dos dados: subdividiram-se as tarefas de tradução (32 ao todo) em três fases (orientação, redação e revisão) e fizeram-se cálculos para cada uma dessas fases (i.e., 96 atividades). Dessa forma, foi possível determinar diferenças (e semelhanças) entre indivíduos e grupos em cada uma das três fases de produção.

$\mathrm{Na}$ análise apresentada em Jakobsen (2003), a velocidade total de tradução dos tradutores profissionais, ao contrário do que se esperava, não se mostrou significativamente mais rápida do que a do grupo de semiprofissionais. A análise aqui relatada ajuda a explicar

\footnotetext{
${ }^{1}$ Agradecemos ao autor a gentileza de ceder os direitos para a publicação desta versão traduzida. Referência do artigo original: JAKOBSEN, Arnt Lykke. Translation drafting by professional translators and by translation students. In: HANSEN, Gyde (Ed.). Empirical translation studies: process and product. Copenhagen: Samfundslitteratur, 2002. p. 191-204.

${ }^{2}$ Copenhagen Business School

3 Tradutora do inglês. Possui Bacharelado em Tradução pela Universidade Federal da Paraíba (2014). Experiência com tradução de textos acadêmicos e legendas. E-mail: liaradebrito@gmail.com. Tradução supervisionada pela Prof $^{\mathrm{a}}$ Dr $^{\mathrm{a}}$ Tânia Liparini Campos.

${ }^{4}$ Para mais detalhes sobre as condições dos experimentos, cf. Jakobsen (2003), também traduzido neste volume.

${ }^{5}$ Informações sobre o programa Translog podem ser encontradas, em inglês, em Jakobsen (1998, 1999a, e 1999b) e em <http://www.translog.dk>. Jakobsen (1999a) encontra-se traduzido para português neste volume.
} 
esse resultado mostrando que tradutores expertos, apesar de elaborarem a primeira versão de suas traduções bem mais rápido do que os alunos de tradução, despenderam relativamente mais tempo na revisão final do que os alunos. Isso reduziu a velocidade total de tradução dos tradutores profissionais, conforme demonstrado em Jakobsen (2003).

\section{As três fases de produção}

Os dados do registro de acionamentos de teclas e mouse durante as atividades de digitação possibilitam a identificação clara de três diferentes fases no processo tradutório: uma fase inicial de orientação, uma fase intermediária de redação (drafting) e uma fase final de revisão e monitoramento (cf. KRINGS, 2001; MOSSOP, 2001).

A fase inicial de orientação, fase 1, é o intervalo de tempo entre a disponibilização do texto-fonte na tela e a digitação da primeira tecla de produção do texto. Os dois únicos tipos de acionamentos que podem ocorrer aqui são cliques do mouse para rolar o texto-fonte e para ajustar o tamanho da janela do texto-fonte. A rolagem do texto é necessária se o tradutor desejar ler mais do texto-fonte do que mostrado inicialmente na janela onde ele pode ser visualizado. Dados dessa fase indicam quanto do texto-fonte o tradutor observou antes de começar a tradução e quanto tempo foi despendido para isso. Na fase inicial de orientação, predominam atividades de compreensão. Alguma preparação cognitiva da produção do textoalvo pode estar envolvida, mas, na nossa definição, não pode haver digitação do texto-alvo nessa fase.

Se a fase inicial de orientação é tratada como uma fase separada ou como parte da fase de redação (fase 2) é uma questão de definição. A pausa inicial é frequentemente mais longa do que aquelas encontradas mais adiante, entre segmentos de produção textual. Isso indica que o processamento de texto que acontece no início é muitas vezes de um tipo diferente daquele refletido pelas pausas mais curtas encontradas mais adiante na fase 2. Não obstante, pausas iniciais são frequentemente bem curtas, de fato algumas vezes mais curtas do que aquelas encontradas na fase 2. O presente artigo inclui considerações sobre os dados da fase 1 porque a atividade cognitiva nessa fase deve ser considerada uma preliminar importante para o processamento textual que acontece na fase de redação propriamente dita.

A fase 2, a fase intermediária, de redação, vai da digitação da primeira tecla de produção do texto até a primeira digitação do último ponto final (ou tecla equivalente). Geralmente, o fim da fase de redação pode ser identificado sem ambiguidade e é claramente visualizado na representação dos dados, já que a digitação do último ponto final é tipicamente 
seguida por uma grande quantidade de movimentos de cursor (por meio das setas de navegação do teclado, cliques do mouse, etc.) indicando que o texto-alvo está sendo monitorado e reformulado.

$\mathrm{Na}$ fase de redação, podem ocorrer acionamentos de vários tipos, a saber: produção textual (por meio de teclas de caracteres, incluindo espaços e "Enter" para criar uma nova linha), eliminação de texto (por meio de "Delete", "Backspace" etc.), navegação do cursor (por meio das setas do teclado), cliques do mouse e operações de recortar, copiar ou colar. Nessa fase, o texto é digitado, mas geralmente não tão uniformemente. Mudanças são feitas, erros de digitação são corrigidos, texto existente é excluído e substituído por novo texto, e algumas vezes o fluxo de produção é momentaneamente interrompido enquanto várias fontes externas (dicionários, internet etc.) são consultadas. Tudo isso cria o "ritmo cognitivo" característico da produção textual (cf. SCHILPEROORD, 1996, p. 5). Assim, a redação não é apenas produção textual; inclui também muita revisão textual, que proponho chamar de revisão on-line (em tempo real, imediata), pois ela é efetuada enquanto a primeira versão completa do texto ainda não foi finalizada.

$\mathrm{Na}$ terceira fase, a fase final de revisão, há uma clara mudança de ritmo. Nesse momento, o texto que foi escrito na fase intermediária é revisado. Tipicamente, a velocidade de produção textual é consideravelmente menor do que aquela da fase intermediária, pois a atividade principal é o monitoramento do texto já existente. Essa atividade geralmente inclui uma grande quantidade de novas consultas ao texto-fonte. Fontes de consulta também podem ser novamente utilizadas em uma nova tentativa de lidar com os problemas que não foram resolvidos ou de validar uma solução proposta. Quando necessário, material texto é excluído e substituído por soluções alternativas, e a formatação, a ortografia e a pontuação são ajustadas. Essa fase dura até o tradutor decidir que a tradução está finalizada e pronta para ser entregue.

\section{Quantidade de tempo despendido em cada fase}

No grupo dos alunos de tradução, grupo S, os participantes dedicaram entre $1 \%$ e 3\% do seu tempo total de produção à fase inicial de orientação, sendo a média de 1,7\%. Entre $73 \%$ e $85 \%$ foram dedicados à fase intermediária, de redação, independentemente da condição de verbalização do pensamento em voz alta, da direção da tradução, da sequência das tarefas ou do texto. No entanto, enquanto a variação no tempo despendido na fase intermediária não foi tão marcante, houve diferenças substanciais na quantidade de tempo destinado à revisão final. Os participantes 1 e 2 dedicaram, cada um, em torno de $25 \%$ do seu tempo total de 
produção à revisão final, enquanto os participantes 3 e 4 dedicaram apenas 13\%, uma diferença relevante o suficiente para sugerir uma diferença no estilo de trabalho ou perfil do tradutor: um que prioriza a redação fluente da primeira versão, e um que investe tempo em uma análise profunda dos problemas assim que surgem.

O padrão geral para o grupo de tradutores profissionais foi o de dedicar um pouco mais de tempo à orientação inicial (média 2,5\%; variação de $0,4 \%$ a $10,2 \%$ ) e um pouco mais de tempo à revisão final do que os alunos de tradução ${ }^{6}$. Enquanto a média para os alunos de tradução foi um pouco abaixo de $19 \%$, os profissionais despenderam quase $24 \%$ do tempo de produção na revisão final (variação de $14 \%$ a $35 \%$ ). Em uma tarefa, um dos profissionais despendeu mais tempo fazendo a revisão final do que de fato redigindo a primeira versão, o que foi ainda mais notável pelo fato de nenhuma mudança ter sido feita.

Apesar de os profissionais apresentarem traduções muito superiores no final da fase 2 (o que pode ser observado até mesmo por meio de uma análise qualitativa muito superficial), eles, ainda assim, despenderam relativamente mais tempo conferindo seus textos do que os não profissionais. Apenas uma análise qualitativa completa dos dados, que vai além do escopo do presente artigo, pode revelar a extensão total de tais diferenças, mas uma hipótese do que esses tradutores profissionais fazem é monitorar e aperfeiçoar um texto que já se encontra completamente funcional. Os alunos de tradução também monitoram seu texto-alvo durante a revisão final, mas nessa fase eles ainda estão frequentemente lidando com problemas não solucionados ou apenas parcialmente solucionados.

\section{Duração da fase 1}

A duração média da fase inicial, para as 32 traduções, foi de 24,4 s, ou $2 \%$ do tempo total despendido na elaboração das traduções. Apesar de os textos-fonte serem bem pequenos, com 367 a 1001 caracteres, 24,4 s não seriam suficientes para que os tradutores lessem todo o texto antes de começarem a traduzi-lo. Mesmo em situações experimentais e com textos bem curtos, os tradutores não prestaram atenção às advertências dos professores de tradução para que se leia todo o texto-fonte antes de se proceder à sua tradução. Em 13 casos, a fase de orientação inicial durou menos de $10 \mathrm{~s}$, tendo a mais curta a duração de 3,5 s. O grupo de alunos de tradução como um todo despendeu menos do que a média nessa fase $(23,0 \mathrm{~s})$, enquanto o grupo de tradutores profissionais como um todo despendeu um pouco mais $(25,7 \mathrm{~s})$.

\footnotetext{
${ }^{6}$ Jensen (2001), cf. também Jarvella et al. (2002), encontrou uma distribuição semelhante.
} 
A variação individual, tanto para um mesmo participante quanto entre participantes, foi, em alguns casos, muito considerável. O participante 4 despendeu 8,7 s se preparando para traduzir o texto 3 (760 caracteres) e 55,4 s no texto 2 (522 caracteres). O participante 5 hesitou por 3,8 s antes de começar a traduzir o texto 1 (367 caracteres) e 135,1 s antes de começar o texto 4 (1001 caracteres). O participante 6 começou o texto 1 depois de $3,7 \mathrm{~s}$ e o texto 4 depois de $9,0 \mathrm{~s}$.

As fases iniciais abaixo da média estiveram quase todas relacionadas com os textos 1, 2 e 3, com exceção dos participantes 4 e 8 , que despenderam um tempo acima da média na fase inicial nos textos 1 e 2 e nos textos 2 e 3, respectivamente. Em contrapartida, todos os participantes (exceto 6 e 7) despenderam tempo na fase inicial acima da média no texto 4 . Apesar de isso poder ter sido parcialmente causado pelo tamanho do texto 4 (1001 caracteres), é provável que outros fatores também tenham influenciado.

Enquanto a média das pausas da fase inicial dos profissionais correspondeu de maneira aproximadamente proporcional aos tamanhos dos textos-fonte (quanto maior o texto-fonte, maior a fase de orientação), esse não foi o caso no grupo dos alunos de tradução. A direção da tradução (L1-L2 para os textos 1 e 2; L2-L1 para os textos 3 e 4) também não pareceu ser um fator interveniente no experimento, assim como a condição de verbalização do pensamento em voz alta $^{7}$. Apesar de a sequência das tarefas, em alguns casos, parecer ter tido influência nas pausas iniciais, também não pode ser verificado efeito consistente em relação a esse fator. A explicação mais provável, portanto, é que a maioria dos participantes sentiu que algo relativo ao conteúdo especializado (eleição presidencial nos EUA) do texto 4 requeria uma pesquisa inicial mais minuciosa para compreensão do texto, antes de eles se sentirem aptos a procederem à tradução.

Os tempos médios da fase inicial para cada um dos quatro textos estão apresentados, por grupo, na Tabela 1.

\footnotetext{
${ }^{7}$ Os alunos de tradução traduziram os textos 1 e 4 enquanto simultaneamente verbalizavam o pensamento em voz alta, e os profissionais fizeram verbalizações simultâneas enquanto traduziam os textos 2 e 3 . O presente artigo não considera dos dados das verbalizações obtidas nesse experimento.
} 
Tabela 1 - Média do tempo de pausa da fase inicial por texto do grupo de alunos de tradução e do grupo de tradutores profissionais

\begin{tabular}{l|l|l|l}
\hline Texto & Alunos de tradução & Profissionais & Média \\
\hline $\mathbf{1}$ & 24,80 & 7,88 & 16,34 \\
\hline $\mathbf{2}$ & 19,96 & 20,53 & 20,25 \\
\hline $\mathbf{3}$ & 10,75 & 25,71 & 18,23 \\
\hline $\mathbf{4}$ & 36,65 & 48,64 & 42,65 \\
\hline Média & $\mathbf{2 3 , 0 4}$ & $\mathbf{2 5 , 6 9}$ & $\mathbf{2 4 , 3 6}$ \\
\hline
\end{tabular}

Assim, os tradutores profissionais, como um grupo, investiram mais tempo do que os alunos de tradução na orientação inicial. Além disso, enquanto o tempo despendido nessa fase pelos tradutores profissionais foi quase que proporcional ao tamanho dos textos-fonte, não houve tal correlação no grupo de alunos de tradução.

Individualmente, os tempos de pausa da fase inicial dos participantes variaram conforme disposto na Tabela 2.

Tabela 2 - Tempo de pausa da fase inicial por participante

\begin{tabular}{l|l|l|l}
\hline Participante & Alunos de tradução & Profissionais & Participante \\
\hline $\mathbf{1}$ & 22,15 & 40,37 & $\mathbf{5}$ \\
\hline $\mathbf{2}$ & 13,31 & 12,59 & $\mathbf{6}$ \\
\hline $\mathbf{3}$ & 14,36 & 9,56 & $\mathbf{7}$ \\
\hline $\mathbf{4}$ & 42,34 & 40,24 & $\mathbf{8}$ \\
\hline Média & $\mathbf{2 3 , 0 4}$ & $\mathbf{2 5 , 6 9}$ & Média \\
\hline
\end{tabular}

A média para os dois grupos não foi tão diferente $(23,0 \mathrm{~s}$ contra $25,7 \mathrm{~s})$, mas as diferenças individuais foram consideráveis. Os participantes 4, 5 e 8 pausaram por uma média de 40 a $42 \mathrm{~s}$, enquanto os participantes 2, 3, 6 e 7 pausaram por apenas 10 a $14 \mathrm{~s}$. Apesar de essas diferenças serem consideráveis e poderem ser indicativas de estilos de trabalho diferentes entre os tradutores, é preciso lembrar que o tempo investido na fase inicial foi insignificante em comparação com o tempo despendido nas duas outras fases.

\section{Duração da fase 2}

A duração média da fase intermediária, a principal, para todas as 32 traduções, foi de 911,1 s. Isto é, $77 \%$ do tempo total destinado à tarefa foi usado na fase principal, de redação.

Entretanto, subjacente à média, houve variações interessantes. Primeiramente, houve diferença substancial entre o tempo usado pelo grupo de alunos de tradução (média de $1043 \mathrm{~s}$ ) e aquele investido pelo grupo de tradutores profissionais (média de 779 s). 
Tabela 3 - Tempo médio (em segundos) por participante na fase 2 para os dois grupos

\begin{tabular}{l|l|l|l}
\hline Participante & Alunos de tradução & Profissionais & Participante \\
\hline $\mathbf{1}$ & 1118 & 776 & $\mathbf{5}$ \\
\hline $\mathbf{2}$ & 952 & 711 & $\mathbf{6}$ \\
\hline $\mathbf{3}$ & 746 & 1069 & $\mathbf{7}$ \\
\hline $\mathbf{4}$ & 1325 & 558 & $\mathbf{8}$ \\
\hline Média & $\mathbf{1 0 4 3}$ & $\mathbf{7 7 9}$ & Média \\
\hline
\end{tabular}

Mesmo que um dos alunos de tradução (S3) tenha sido muito rápido em comparação com os outros membros do grupo, dois dos profissionais (S6 e S8) foram ainda mais rápidos. Além disso, mesmo que um dos profissionais (S7) tenha sido excepcionalmente lento em comparação com os outros, dois dos alunos de tradução (S1 e S4) foram ainda mais lentos.

$\mathrm{Na}$ fase intermediária, o tempo despendido na elaboração da primeira versão do texto-alvo dependeu de três fatores em particular (além do nível de expertise do tradutor). Foram eles: o tamanho do texto-fonte; o fato de o tradutor estar verbalizando ou não o pensamento em voz alta; e a direção da tradução (direta ou inversa).

Os tempos de redação por texto estão dispostos na Tabela 4.

Tabela 4 - Tempo médio (em segundos) por texto na fase 2 para os dois grupos de participantes

\begin{tabular}{l|l|l}
\hline Texto & Alunos de tradução & Profissionais \\
\hline $\mathbf{1}$ & 745 & 390 \\
\hline $\mathbf{2}$ & 818 & 794 \\
\hline $\mathbf{3}$ & 1034 & 973 \\
\hline $\mathbf{4}$ & 1576 & 959 \\
\hline Média & $\mathbf{1 0 4 3}$ & $\mathbf{7 7 9}$ \\
\hline
\end{tabular}

Em geral, quanto maior o texto-fonte, mais tempo o tradutor precisou para completar a primeira versão da tradução. Os dois textos-fonte em dinamarquês (1 e 2, na Tabela 4) tinham 367 e 522 caracteres (incluindo espaços), respectivamente. Os dois textos-fonte em inglês (3 e 4, na tabela) eram um pouco mais longos (760 e 1001 caracteres, respectivamente).

Já que os textos-fonte têm tamanhos bem diferentes, os números na Tabela 4 não são comparáveis. Uma melhor visualização da duração relativa das tarefas na fase 2 foi obtida por meio do cálculo dos valores da duração para cada 100 caracteres do texto-fonte (cf. Tabela 5). 
Tabela 5 - Tempo médio (em segundos) para cada 100 caracteres do texto-fonte para os dois grupos de participantes

\begin{tabular}{l|l|l}
\hline Texto & Alunos de tradução & Profissionais \\
\hline $\mathbf{1}$ & 203 & 106 \\
\hline $\mathbf{2}$ & 157 & 152 \\
\hline $\mathbf{3}$ & 136 & 128 \\
\hline $\mathbf{4}$ & 157 & 96 \\
\hline Média & $\mathbf{1 6 3 , 2 5}$ & $\mathbf{1 2 0 , 5}$ \\
\hline
\end{tabular}

Esses dados mostram que a diferença no tempo despendido na fase de redação dos textos 1 e 4 foi considerável entre os grupos. Nesse caso, os tradutores profissionais despenderam muito menos tempo do que os alunos de tradução. Todavia, para os textos 2 e 3 a diferença foi pequena.

A principal causa dessas diferenças foi o fato de os alunos de tradução terem redigido as traduções dos textos 1 e 4 enquanto verbalizavam, enquanto os profissionais redigiram suas traduções dos textos 2 e 3 enquanto verbalizavam. Ao contrário do que se acreditava ${ }^{8}$, a verbalização do pensamento em voz alta desacelerou consideravelmente a produção da tradução no nosso experimento. É por isso que a diferença entre os dois grupos de participantes foi exagerada em relação aos textos 1 e 4, entre os quais o processo de tradução dos alunos foi mais lento devido à verbalização simultânea do pensamento em voz alta, e minimizada em relação aos textos 2 e 3 , entre os quais o processo de tradução dos profissionais foi mais lento devido a essa verbalização simultânea.

As diferenças individuais foram consideráveis. Os participantes 1, 2 e 3 trabalharam mais rápido (cerca de $23 \%$ ) quando traduziram sem verbalizar, independentemente da direção da tradução. O mesmo também aconteceu com S4, exceto no caso do texto 2, que teve a sua tradução mais lenta devido à dificuldade do participante com expressões desconhecidas em um texto sobre futebol, expressões essas que os outros participantes acharam bastante acessível.

A diferença geral a respeito do tempo despendido na fase 2 foi que os alunos de tradução despenderam acima de $35 \%$ a mais de tempo do que os profissionais.

Efeitos da direção da tradução também foram observados nessa fase. Nos dois grupos, a tradução L1-L2 (textos 1 e 2) exigiu relativamente mais tempo do que a tradução L2-L1.

\footnotetext{
${ }^{8}$ Com base na hipótese fundamental de Ericsson e Simon (1993 [1984], p. 63) de que "[q]uando o processador central serve ou ativa uma estrutura na memória que é apenas codificada oralmente, essa estrutura pode, então, ao mesmo tempo ser vocalizada abertamente sem fazer exigências adicionais em termos de tempo ou de capacidade de processamento. Quando os conteúdos da memória de curto prazo são palavras (i.e., são codificados oralmente), podemos, a qualquer momento, dizer essas palavras sem interferência do processo em andamento".
} 
A redação da tradução da L1 para a L2 foi geralmente mais lenta do que a redação da L2 para a L1 em uma média de cerca de 23\% (179,9 s a cada 100 caracteres do texto-fonte no sentido L1 para L2, contra 146,6 no sentido L2 para L1). Todos os participantes (exceto S4) despenderam a maior parte do tempo (a cada 100 caracteres do texto-fonte) na fase de redação da tradução no caso do texto 1. Conforme já mencionado, a redação de S4 no texto 2 foi excepcionalmente lenta, mas, ignorando esse texto, a redação do texto 1 de S4 também foi mais lenta do que qualquer outra. $\mathrm{O}$ texto 2 pode não ter sido uma seleção de texto ideal, em especial no caso de S4.

A variação das velocidades de redação entre os participantes do grupo $\mathrm{S}$ foi a seguinte:

- Texto 1 (L1 para L2, com verbalização do pensamento em voz alta): 175 a 244 s a cada 100 caracteres do texto-fonte (CTF);

- Texto 2 (L1 para L2, sem verbalização do pensamento em voz alta): 81 a 260 (158) s a cada $100 \mathrm{CTF}$;

- Texto 3 (L2 para L1, sem verbalização do pensamento em voz alta): 105 a 170 s a cada $100 \mathrm{CTF}$;

- Texto 4 (L2 para L1, com verbalização do pensamento em voz alta): 110 a 187 s a cada $100 \mathrm{CTF}$.

Mesmo que a fase de redação do texto 2 excepcionalmente lenta de S4 (260 s a cada $100 \mathrm{CTF}$ ) fosse desconsiderada, o texto 2 revelou a maior variação relativa e parece ter apresentado os dados menos generalizáveis dos experimentos.

No grupo dos tradutores profissionais, os resultados foram bem diferentes, sendo um fator importante que os profissionais traduziram todos os textos em condições de verbalização opostas àquelas que se aplicaram aos alunos de tradução. A comparação, texto a texto, entre os grupos no que diz respeito aos desempenhos na fase de redação teve que levar em conta o efeito considerável dessa condição.

No grupo dos profissionais, a fase de redação foi cerca de $40 \%$ mais lenta por causa da verbalização do pensamento em voz alta (140 s a cada 100 CTF com verbalização, contra 101 s sem verbalização). A fase de redação da L2 para a L1 também foi geralmente mais rápida nesse grupo do que aquela da L1 para a L2 (por cerca de $15 \%$; 129 s a cada $100 \mathrm{CTF}$, contra $112 \mathrm{~s})$.

Mais uma vez, houve diferenças individuais consideráveis e, às vezes, inesperadas. Contudo, em geral, a verbalização do pensamento em voz alta tornou a redação muito mais lenta do que a condição de tradução no sentido L1 para L2. 
S5 despendeu relativamente mais tempo (136 s a cada $100 \mathrm{CTF}$ ) na fase de redação do texto 1 do que na mesma fase de qualquer outro texto. S6 e S8 seguiram o padrão predominante no que diz respeito aos efeitos da verbalização simultânea (mais tempo despendido na redação com verbalização do que sem), mas, nos dois casos sem verbalização, a redação das tarefas da L1 para a L2 foi realizada mais rapidamente do que no caso das tarefas da L2 para a L1. S8 levou uma média de 77 s para redigir a tradução a cada 100 CTF. Em geral, S8 trabalhou muito rápido; e apesar de a redação do texto 2 ter sido realizada rapidamente mesmo para os padrões de S8, ela não foi excepcional. Em contrapartida, a fase de redação do texto 2 de S7 foi excepcionalmente lenta (270 s a cada $100 \mathrm{CTF}$ ), quase duas vezes mais lenta do que a segunda mais lenta (no grupo dos profissionais) e cerca de três vezes e meia mais lenta do que a mais rápida. Esse foi outro indício de que o tema futebol do texto 2 apresentou desafios bem diferentes para os participantes desse experimento.

Outro potencial fator distrator pode ter sido o tamanho dos textos neste experimento. Os textos 1 e 2 eram mais curtos e, portanto, mais sensíveis a interferências acidentais durante a tarefa de tradução. Apesar de isso não ter sido evidente nos dados do grupo $\mathrm{S}$, os dados do grupo dos profissionais, grupo $\mathrm{X}$, poderiam ser interpretados dessa maneira. S6 e S8 redigiram o texto 1 muito rapidamente $(69 \mathrm{~s}$ e $50 \mathrm{~s}$, respectivamente, a cada $100 \mathrm{CTF})$, enquanto S5 e S7 levaram aproximadamente o dobro desse tempo (136 s e $170 \mathrm{~s}$ a cada 100 CTF).

No grupo X, a variação das velocidades da redação entre os participantes foi a seguinte:

- Texto 1 (L1 para L2, sem verbalização do pensamento em voz alta): 50 a 170 s a cada $100 \mathrm{CTF}$;

- Texto 2 (L1 para L2, com verbalização do pensamento em voz alta): 77 a 270 (144) s a cada 100 CTF;

- Texto 3 (L2 para L1, com verbalização do pensamento em voz alta): 117 a 138 s a cada $100 \mathrm{CTF}$;

- Texto 4 (L2 para L1, sem verbalização do pensamento em voz alta): 76 a 120 s a cada $100 \mathrm{CTF}$.

Assim, apesar de o efeito retardador da verbalização simultânea sobre a fase de redação ter sido maior no caso dos profissionais do que no caso dos alunos de tradução e apesar de os profissionais terem redigido textos-alvo consideravelmente mais longos, os tradutores profissionais, desconsiderando-se todas as diferenças qualitativas, utilizaram cerca 
de $40 \%$ a menos de tempo para redigir as traduções no sentido da L1 para a L2 e cerca de $30 \%$ a menos de tempo para redigir as traduções no sentido da L2 para a L1.

Uma análise de variância ANOVA 2x2×2 baseada nos números da Tabela 5 mostrou o efeito simples significativo do fator verbalização entre os participantes do mesmo grupo $(\mathrm{F}=15,99 ; \mathrm{p}=0,007)$, enquanto o efeito da direção da tradução não atingiu níveis significativos $(\mathrm{F}=2,87 ; \mathrm{p}=0,14)$. Apesar de a diferença entre grupos, no nível geral de expertise, se mostrar mais clara do que na análise anterior, essa diferença também não atingiu significância estatística $(\mathrm{F}=2,23 ; \mathrm{p}=0,19)$, provavelmente por causa do tamanho reduzido da amostra. Nenhuma interação significativa entre os efeitos foi encontrada.

\section{Revisão on-line (revisão na fase 2)}

Para cada 100 caracteres na versão final do texto-alvo, o grupo de alunos de tradução acionou uma média de 126 teclas de produção. Se incluirmos as teclas de navegação, as teclas de exclusão de texto, os cliques de mouse etc., a média foi de 140 acionamentos para cada 100 caracteres do texto-alvo final. Os profissionais tiveram apenas 115 acionamentos de teclas produção para cada 100 caracteres do texto final (130 se considerarmos teclas de navegação de cursor etc.). Embora a quantidade de navegações do cursor etc. tenha sido basicamente a mesma nos dois grupos, a quantidade de revisão on-line do texto foi quase duas vezes maior no grupo dos alunos de tradução do que no grupo de tradutores profissionais, indicando uma incerteza maior por parte dos participantes daquele grupo.

Individualmente, os alunos de tradução agiram de maneira bastante semelhante. Um participante nesse grupo foi um pouco mais lento do que os outros e também revisou menos (119 acionamentos de teclas de produção a cada 100 caracteres do texto-alvo final). Em contrapartida, as versões finais dos textos-alvo dos outros participantes desse grupo tiveram entre $25 \%$ e $30 \%$ menos caracteres do que o número de acionamentos de teclas de produção na fase 2, indicando uma grande quantidade de revisão on-line.

No grupo dos profissionais, os textos-alvo finais de dois participantes, ambos muito rápidos na produção textual (e do sexo feminino), tiveram em média apenas 7\% e 9\% de caracteres a menos do que todos os caracteres digitados na fase 2. Em contrapartida, os outros dois participantes (ambos do sexo masculino) descartaram 18\% e $25 \%$ da sua produção textual durante a fase de redação.

Entre os textos, a quantidade de revisão on-line foi bem distribuída dentro de cada grupo. Os alunos de tradução ponderaram mais enquanto traduziram o texto 4 e, portanto, 
digitaram apenas $21 \%$ de texto em excesso nesse caso, em oposição a $27 \%-29 \%$ nos outros. A quantidade de revisão on-line em cada texto feita pelos profissionais foi praticamente idêntica (entre $14,5 \%$ e $15,1 \%$ ).

As diferenças que resultaram da condição de verbalização do pensamento em voz alta ou da direção da tradução foram pequenas, mas consistentes. Os dois grupos fizeram mais revisão na condição sem verbalização do que naquela com verbalização simultânea $(27,8 \%$ contra $24,2 \%$ no grupo dos alunos de tradução; $15,0 \%$ contra $14,6 \%$ no grupo dos profissionais). Semelhantemente, os dois grupos fizeram um pouco mais de revisão na direção L1-L2 (26,9\% contra 25,0\%; 14,9\% contra 14,6\%, respectivamente). Apesar de as diferenças terem sido mínimas, elas sugerem que tanto a condição L1-L2 quanto a condição de verbalização simultânea fizeram com que os participantes revisassem mais antes de se darem por satisfeitos com o texto-alvo.

\section{Conclusão}

Apesar de a análise quantitativa dar apenas uma visão incompleta do desempenho superior dos tradutores profissionais em comparação ao desempenho dos alunos de tradução, que têm menos experiência, desenvoltura e habilidade, tal análise, ainda assim, ajuda a determinar aspectos importantes do desempenho dos tradutores profissionais. De um modo geral, pôde-se observar uma diferença na alocação geral do tempo e do esforço cognitivo às três fases de tradução. Em termos relativos e em termos absolutos, mais tempo foi dedicado pelos profissionais à orientação inicial; e em termos relativos, mas não em termos absolutos, mais tempo foi envidado na revisão final.

A fase na qual os tradutores profissionais demonstraram mais claramente seu conhecimento experto foi a fase de redação. Os tradutores profissionais não apenas produziram o texto-alvo mais rapidamente do que os alunos de tradução, mas também produziram textos mais duráveis. Uma vez que uma solução tivesse sido encontrada e o censor interno do tradutor permitisse que ela fosse digitada, era mais provável que ela fosse mantida até a versão final do texto-alvo, ao passo que as soluções produzidas pelos alunos de tradução eram mais voláteis e provisórias. A análise das fases do processo tradutório também indicou que, apesar da habilidade dos tradutores profissionais de produzir soluções mais sustentáveis na fase de redação, relativamente mais tempo foi dedicado às tarefas de monitoramento. 
Por fim, o novo método de análise confirmou resultados anteriores sobre o efeito da verbalização simultânea do pensamento em voz alta sobre o processo tradutório. A verbalização simultânea foi um constrangimento grave para todos os participantes (menos um) e foi mais desconcertante para os tradutores profissionais do que para os alunos. O efeito foi particularmente perceptível na fase de redação: analisando os dados dessa fase separadamente, foi possível demonstrar a significância estatística do efeito da verbalização simultânea na fase de redação da tradução $(p=0,007)$.

\section{Referências}

ERICSSON, KARL A.; SIMON, HERBERT A. Protocol analysis: verbal reports as data. ed. rev. Cambridge: MIT Press, 1993 [1984].

HANSEN, G. (Ed.). Probing the process in translation: methods and results. Copenhagen: Samfundslitteratur, 1999.

JAKOBSEN, A. L. Logging time delay in translation. In: HANSEN, G. (Ed.) LSP Texts and the Process of Translation, Copenhagen Working Papers in LSP 1. Copenhagen: Copenhagen Business School, 1998, p. 73-101.

JAKOBSEN, A. L. Logging target text production with Translog. In: HANSEN, G. (Ed.). Probing the process in translation: methods and results. Frederiksberg: Samfundslitteratur, 1999a. p. 9-20.

JAKOBSEN, A. L.; SCHOU, L. Translog documentation: version 1.0. In: HANSEN (Ed.). Probing the process in translation: methods and results. Copenhagen: Samfundslitteratur, 1999b. p. 151-186. Appendix.

JAKOBSEN, A. L. Effects of think aloud on translation speed, revision and segmentation. In: ALVES, F. (Ed.) Triangulating translation: perspectives in process oriented research. Amsterdã: John Benjamins, 2003. p. 69-89.

JARVELLA, R. J.; JENSEN, A.; JENSEN, E. H.; ANDERSEN, M. S. Towards characterizing translation expertise, knowledge and know-how: some findings using TAPs and experimental methods. In: RICCARDI, A. (Ed.). Translation studies. Cambridge: Cambridge University Press, 2002. p. 172-197.

JENSEN, A. The effects of time on cognitive processes and strategies in translation. Copenhagen: Copenhagen Business School, 2001.

KRINGS, H. P. Repairing texts: empirical investigations of machine translation post-editing processes. Tradução de Geoffrey S. Koby, George M. Shreve, Katja Mischerikow e Sarah Litzer. Kent, Ohio: Kent State University Press, 2001.

MOSSOP, B. Revising and editing for translators. Manchester: St. Jerome, 2001. 
SCHILPEROOD, J. It's about time: temporal aspects of cognitive process in text production. Amsterdã: Rodopi, 1996.

TIRKKONEN-CONDIT, S. Process research: state of the art and where to go next? Across Languages and Cultures, v. 3, n. 1, p. 5-9, 2002.

TIRKKONEN-CONDIT, S.; JÄÄSKELÄINEN, R. (Ed.). Tapping and mapping the process of translation: outlook on empirical research. Amsterdã: John Benjamins, 2000. 